\title{
Salud y justicia global ${ }^{1}$ Health and Global Justice
}

\author{
Ángel Puyol \\ Universitat Autònoma de Barcelona \\ angel.puyol@uab.cat
}

\begin{abstract}
Resumen. Una de las cuestiones que debería preocupar más a la teoría de la justicia global es la enorme desigualdad de salud que hay en el mundo. En este artículo, se repasan las causas de la desigualdad global de salud y los argumentos éticos a favor y en contra de la necesidad de tratar dicha desigualdad desde la perspectiva de la justicia global. Tras rechazar los argumentos en contra tanto del libertarismo de derechas como del estatalismo, y tras exponer las críticas tanto al lenguaje de los derechos humanos como a la propuesta poggeana de reducir los deberes de la justicia global a deberes morales negativos, defiendo la necesidad de partir de un criterio de justicia global suficientista y basado en los deberes morales positivos para afrontar la gravedad y la urgencia moral que suponen las desigualdades globales de salud.
\end{abstract}

Palabras clave: Justicia global, salud, igualdad, igualitarismo, derechos humanos.
Abstract. A question that would have to worry more to the global justice is the huge inequality of health in the world. In this paper, I analyse the causes of the global inequality of health and the ethical arguments for and against the need to treat this inequality from the perspective of the global justice. After refusing the arguments against both of the libertarianism and the statism, and after showing the critics both to the approach to the language of human rights and to the poggean proposal to reduce the duties of global justice to negative moral duties, I defend the need to use a sufficiency approach to global justice based in positive moral duties to face the severity and the moral urgency of the global inequalities of health.

Key words: Global justice, health, equality, egalitarianism, human rights.

\section{Las causas de la desigualdad global de salud}

«Lo mejor que puede tener un hombre, en mi opinión, es su salud». Así sentenciaba el filósofo presocrático Epicarmo de Siracusa en el siglo V a.c. (Freeman, 1971, 37). Más de dos mil años después, pero siguiendo esa misma estela, Descartes se pronunciaba a favor de «la conservación de la salud, que es, sin duda, el primer bien y el fundamento de todos los otros bienes de esta

1 Este artículo se enmarca en los resultados del proyecto de investigación Batista i Roca PBR2009-0006 Justícia, Igualtat i Globalització de la Generalitat de Catalunya. 
vida» $(1986,86)$. La Organización Mundial de la Salud actualizó en el siglo Xx esas afirmaciones declarando, en su Constitución, que: «el goce del grado máximo de salud que se pueda lograr es uno de los derechos fundamentales de todo ser humano sin distinción de raza, religión, ideología política o condición económica o social». Lamentablemente, ese derecho no siempre se respeta: la salud es un bien repartido muy desigualmente.

La esperanza de vida ha crecido en el mundo durante los últimos cincuenta años, pero su distribución ha sido muy dispar, incluso ha bajado en el África subsahariana y en la Europa del Este. Una persona que hoy nace en Swazilandia puede esperar vivir hasta los 50 años, mientras que si lo hace en Japón o Suecia sobrepasará los 80 años. Esa desigualdad se ceba además en las mujeres y los niños. Así, una mujer que da a luz en el África subsahariana tiene cien veces más probabilidades de morir en el parto que si pare en un país industrializado, y un niño que nace en Angola tiene una probabilidad de morir antes de los cinco años de edad setenta y tres veces mayor que si naciese en Noruega (OMS, 2010). Más de 11 millones de niños mueren cada año en el mundo por enfermedades tratables con éxito como la diarrea o la malaria. Sólo la tubercolosis mata al año casi a dos millones de personas en los países pobres (Schieber et al., 2007). Pero la desigualdad de salud entre pobres y ricos también se reproduce en el interior de cada país. Así, un vecino del barrio obrero de Calton, en Glasgow, tiene una esperanza de vida de 54 años, mucho más baja que los 82 años de sus convecinos del barrio rico de Lenzie N. Los estadounidenses negros viven 63 años de media, mientras que la esperanza de vida del país es de 75 años. En las zonas más ricas de la India, 40 niños de cada 1.000 morirán antes de cumplir los cinco años de edad, mientras que en las zonas más pobres del país la mortandad infantil se eleva a 140 por cada 1.000. En el Perú, la relación es de 20 muertes infantiles de cada 1.000 en los hogares ricos y de 110 de cada 1.000 en los hogares pobres (OMS, 2008).

En los últimos años, ha crecido el interés por averiguar las causas de esa terrible desigualdad. La explicación del paradigma biomédico tradicional, basada en un combinación de causas naturales, responsabilidad individual y falta de atención médica, se ha mostrado absolutamente insuficiente. Como es obvio, no existe una causa natural interna que explique por qué los pobres tienen una salud también pobre. Ni siquiera podemos atribuir la desigualdad de salud a causas naturales externas como las inundaciones, las sequías o los terremotos. Como bien demostró Amartya Sen antes de que lo galardonaran con el Nobel de Economía por esa razón — entre otras-, la desnutrición crónica o el hambre que provocan las sequías y otras calamidades naturales no se deben a una falta de recursos o a una disminución de la producción de alimento en un determinado país, sino al modo en que el país afectado distribuye los alimentos, el derecho a obtenerlos y el poder de hacerlo. Aunque la causa concreta de una determinada enfermedad puede ser una deficiencia vitamínica, la raíz de esa causa a menudo tiene un origen social (Sen, 1981). 
La segunda causa del enfoque biomédico al uso apunta a los estilos de vida para explicar la desigualdad de salud. Es un tema importante porque la salud depende en parte de los estilos de vida diferentes. Si alguien decide mantener una dieta rica en grasas saturadas, practicar deportes de riesgo o consumir alcohol y tabaco y, como efecto de ello, su salud es peor que la de su vecino, que mantiene un estilo de vida más saludable, no parece que la desigualdad de salud que pueda haber entre ambos por ese motivo sea injusta. Sin embargo, la cuestión de la responsabilidad personal en los temas de salud está lejos de ser clara. Por un lado, no es fácil delimitar qué parte de la desigualdad de salud se debe, efectivamente, a la libertad de llevar unos estilos de vida u otros, ya que a menudo éstos vienen determinados, precisamente, por las condiciones sociales y económicas de las personas y los grupos a los que pertenecen. Por ejemplo, los adolescentes suelen iniciar el hábito de fumar impelidos por la necesidad de integración social, y muchas personas llevan una dieta poco saludable debido a una falta de recursos económicos y educativos. Sabemos que la falta de oportunidades sociales, educativas, culturales o de acceso real a la información y a la capacidad real de procesarla correctamente impide a muchas personas saber cómo deben llevar una vida más sana.

Por otro lado, en muchos casos es difícil saber si contraer una enfermedad es fruto de la mala suerte, de las acciones responsables de las personas o de una injusticia. Por ejemplo, podemos pensar que una persona que muere de sida en África o Sudamérica ha tenido mala suerte por haber contraído la enfermedad. Si no ha seguido las recomendaciones sobre las formas de impedir el contagio por vía sexual, podemos pensar también que es responsable de haberla adquirido (al menos es más responsable que si la hubiese contraído en una transfusión de sangre en un hospital negligente). Pero si pensamos que podría haber sobrevivido a la enfermedad si su país o los organismos internacionales le hubiesen dado acceso a los tratamientos más efectivos contra el sida, entonces no está tan claro que su muerte no haya sido una injusticia. En este último caso, necesitamos una teoría de la justicia que nos lo justifique. Por tanto, el impacto de la responsabilidad individual en las desigualdades de salud es relativo a las circunstancias que rodean a los enfermos. Aunque dicha responsabilidad existe, no exime a la sociedad de la responsabilidad de mitigar y, si es posible, eliminar las desigualdades injustas de salud. La responsabilidad personal juega un papel en la creación de las desigualdades de salud, pero es limitado o periférico (Wikler, 2002).

El tercer factor del enfoque biomédico para explicar la desigualdad de salud es la ausencia de una atención sanitaria adecuada. Sabemos que los países pobres adolecen por regla general de un sistema sanitario fuerte. Alrededor de 2.600 millones de personas carecen en el mundo de servicios sanitarios básicos y 2.000 millones no disponen de medicamentos considerados esenciales (Pogge, 2007, 184). Sin duda, es imprescindible fortalecer los sistemas de atención sanitaria para luchar eficazmente contra la desigualdad global de sa- 
lud. Incluso en países ricos como los Estados Unidos, la falta de un sistema sanitario público amplio perjudica seriamente la salud de aquéllos que, por razones económicas, tienen un acceso restringido a la atención médica disponible.

Sin embargo, el acceso a una atención sanitaria de calidad tiene una capacidad explicativa de nuevo limitada para abordar la desigualdad de salud. La prueba es que ésta persiste incluso en los países que disponen de una atención sanitaria universal. Ya hemos visto, por ejemplo, la diferente esperanza de vida que hay entre un barrio rico de Glasgow y uno pobre, pese a la existencia del National Health Service británico, uno de los más progresistas del mundo. En España, con un sistema sanitario de acceso universal, si la mortalidad se comportase como lo hace en las zonas más ricas del país, morirían 35.000 personas menos cada año (SESPAS, 2000). Además, en el último siglo, el acceso universal a la atención sanitaria sólo explica el $20 \%$ de los años ganados en la esperanza de vida en los países que disponen de ella. El resto se ha debido fundamentalmente a las mejoras en las condiciones de vida, sobre todo las higiénicas (Porter, 1997). El acceso universal a una asistencia sanitaria de calidad es un requisito necesario pero insuficiente para paliar las grandes desigualdades de salud.

Las explicaciones tradicionales de la desigualdad de salud suelen centrarse en los factores biomédicos, incluida la atención sanitaria, que son los que mejor dominan los profesionales de la medicina, dejando a un lado los aspectos sociales de la salud, mucho más difíciles de detectar, controlar y cambiar por esos mismos profesionales. Quizá ahí radique una de las razones por las que habitualmente no se ha prestado la atención que merecen los llamados determinantes sociales de la salud. Sin embargo, algunos profesionales sanitarios han mostrado a veces sus dudas, como un médico que, desarrollando su trabajo en Haití, se lamentaba diciendo que «estudiamos las deficiencias en vitaminas, no la reforma agraria que mejoraría las condiciones de salud de la población; estudiamos las patologías, no las fuerzas sociales que hay detrás de los procesos somáticos críticos». Los aspectos sociales tienen un impacto en la salud y sus desigualdades mucho mayor de lo que se pensaba hasta hace poco.

Sin duda, el principal determinante social de la salud es la pobreza. Los datos son abrumadores. Cada año, la pobreza causa directa e indirectamente 18 millones de muertes prematuras, casi un tercio de todas las defunciones humanas. En los años posteriores a la Guerra Fría, murieron (hasta el año 2006) unas 300 millones de personas por el hambre y las enfermedades curables, muchas más que las que lo hicieron por las diferentes guerras durante todo el siglo XX. Y la pobreza sigue creciendo. 2.735 millones de seres humanos viven por debajo de la línea de la pobreza de 2 dólares diarios establecida por el Banco Mundial. En el año 2000, la mitad de los adultos del mundo poseían el 1,1\% de la riqueza global. El ingreso real del 5\% más pobre de la 
población mundial disminuyó un 20\% entre 1988 y 1993 y otro $23 \%$ en el período 1993-1998, mientras que el ingreso per capita global aumentó un 5,2\% y un 4,8\% en esos períodos respectivamente (Pogge, 2007, 185-186). El reciente Informe de la OMS (2008) sobre los determinantes sociales de la salud sitúa la mejoría de las condiciones de vida, que incluye una escolarización universal, un entorno saludable, prácticas justas en materia de empleo, una protección social a lo largo de la vida y, naturalmente, una atención universal de salud, como el primer reto urgente de los gobiernos del mundo para paliar la desigualdad global de salud.

Sin embargo, la erradicación de la pobreza o de sus efectos más perniciosos para la salud, aun siendo el principal objetivo de una buena política de reducción de las desigualdades globales de salud, tampoco es suficiente para acabar con dicha desigualdad. A pesar de que, con tales políticas, la salud de los más pobres mejoraría ostensiblemente, las desigualdades de salud no desaparecerían. Por ejemplo, los trabajadores no cualificados con más de cinco años de desempleo en el barrio de Harlem, en Nueva York, tienen una mortalidad mayor que los miembros de la clase media en Bangladesh, el país más pobre del mundo, a pesar de que los habitantes de Harlem son veinticinco veces más ricos en términos absolutos que la clase media del país asiático. La razón es que la desigualdad de salud no la padecen sólo los más pobres, sino todos los gradientes sociales. Cuanta más alta es la posición social de la persona dentro de su comunidad, mejor es su salud, independientemente del nivel absoluto de riqueza. Hasta el punto de que los millonarios tienen una salud algo peor que los multimillonarios en cualquier país del mundo. Esa correlación fue publicada en Gran Bretaña en los años ochenta del siglo pasado en el Informe Black. Dicho Informe mostró que después de treinta años de universalización del acceso al National Health Service británico, las desigualdades de salud relacionadas con las desigualdades socioeconómicas persistían. En las mismas fechas, el Informe Whitehall demostró que los funcionarios británicos con un nivel profesional superior tenían una mortalidad menor que los funcionarios con un nivel profesional inferior, pese a que todos eran usuarios del mismo sistema sanitario y pese a que las diferencias salariales y de condiciones de vida no explicaban un acceso diferente al resto de bienes básicos. La única explicación razonable de esa persistente desigualdad de salud es el daño para la salud que se deriva de la desigualdad social o de estatus entre ellos (Marmot, 2004). Los estudios posteriores se empeñan en confirmar que las desigualdades de salud correlacionan positivamente con los niveles socioeconómicos, o sea, cuanto más alto es el nivel social y económico de las personas, mejor salud tienen y la esperanza de vida también es mayor (Kawachi y Kennedy, 2002; Wilkinson, 2005; Rodríguez y Urbanos, 2008; Marmot, 2010) ${ }^{2}$.

2 Naturalmente, cabe preguntarse si la introducción de la variable socioeconómica en la medida de la desigualdad de salud no será ya una determinada apuesta ética, es decir, si no estaremos confundiendo la descripción objetiva de los datos recogidos con su explicación nor- 
Ahora bien, aquí aparece una cuestión sorprendente. A pesar de la contundencia de los datos a favor de esa explicación, seguimos sin saber cuáles son las causas. Es decir, ¿por qué las personas con más estatus social y económico viven más años y con mejor salud que las personas con menos estatus social y económico dentro de la misma comunidad? Sabemos que los estilos de vida personal o las conductas de riesgo para la salud explican muy poco. Podríamos pensar que las circunstancias materiales influyen. Es obvio que a más pobreza, peores condiciones de higiene y de acceso a alimentos nutritivos, seguridad laboral, etcétera. Este tipo de explicación tiene mucho peso en términos absolutos, pero sorprendentemente explica poco en términos relativos. Por ejemplo, no explica por qué los ricos tienen peor salud que los muy ricos.

Un tipo de explicación que cada día tiene más relevancia apunta a factores psicosociales. Autores como Richard Wilkinson y Michael Marmot sostienen que el apoyo social y familiar, el control (o sensación de control) sobre el trabajo y sobre la propia vida, y la ansiedad y el estrés por el reconocimiento social, sobre todo en las sociedades más desiguales, son los factores que mejor dan cuenta de la desigualdad de salud. Al menos, esa explicación permite entender por qué la desigualdad de salud afecta a todos los gradientes sociales, es decir, por qué, en todas las sociedades estudiadas, más ricas o más pobres en su conjunto, el $10 \%$ más rico tiene mejor salud que el segundo $10 \%$ más rico, y así sucesivamente. La idea de fondo es que la desigualdad socioeconómica es la principal causante de la desigualdad de salud, aunque no sabemos exactamente por qué.

A esta explicación cabría plantearle si no estaremos cometiendo de nuevo un pecado metodológico. Tal vez la explicación buena es la inversa, es decir, que la desigualdad de salud es la que explica la desigualdad socioeconómica. Al fin y al cabo, es lícito pensar que las personas enfermas o con mala salud van a tener menos oportunidades sociales y económicas que las sanas. Sin embargo, los estudios sobre la relación entre la salud en la infancia y la posición socioeconómica que ocupan esos niños al alcanzar la vida adulta descartan esa explicación inversa. Los niños ricos y enfermizos tienen más probabilidades de llegar a niveles socioeconómicos altos que los niños pobres con una salud de hierro. Así pues, la condición socioeconómica de los individuos se está mostrando como el factor decisivo para explicar las grandes desigualdades de salud.

mativa. Tal vez sería mejor comparar las desigualdades de salud entre los individuos y no entre los grupos, sin presuponer las causas explicativas en la misma recogida de los datos. Hay que decir, no obstante, que si bien ésta es una cuestión que todo científico social debe tener presente, las múltiples formas de recogida de datos sobre desigualdades de salud se empeñan en seguir corroborando la fuerte relación entre las desigualdades de salud y las desigualdades socioeconómicas. 


\section{La salud global une a libertarios y a hobbesianos}

Sin embargo, pese a que la desigualdad global de salud tiene su origen sobre todo en la desigual e injusta distribución global de los privilegios sociales y económicos, no existe unanimidad académica acerca de si debemos considerar injusta a la desigualdad global de salud. Dos argumentos ponen en duda que la distribución desigual de los determinantes sociales de la salud sea injusta en el contexto global: el argumento libertario de derechas y el argumento del estatalismo.

Los libertarios de derechas excluyen la atención sanitaria de los derechos de las personas porque piensan que no es una exigencia del derecho fundamental a la libertad personal. Todo lo contrario, creen que el acceso universal y subvencionado a la atención sanitaria viola el derecho a la libertad personal, puesto que implica una redistribución de los recursos privados sobre los que las personas tienen derechos de propiedad. Para este tipo de libertarismo, toda acción colectiva sobre la distribución de los recursos privados que ignore la adhesión voluntaria de los afectados representa una imposición injustificada (Nozick, 1978). Imaginemos que una niña desarrolla una enfermedad de origen genético que requiere de un tratamiento caro para intentar restablecer su salud. Para el libertario de derechas, padecer una enfermedad no otorga per se ningún derecho de justicia que los demás estén obligados a proteger. Nadie tiene el deber de ayudar a esa niña más allá de lo que dicte la conciencia personal de cada cual. Cualquier tipo de asistencia sanitaria que se le pueda ofrecer será el resultado de la caridad o la beneficiencia, pero no de la justicia. El argumento libertario de derechas insiste en que sólo debe restituir quien perjudica y, por consiguiente, si no podemos hacer a nadie directamente responsable de la mala salud de otra persona, el enfermo no tiene derecho a ser compensado por terceros. El ámbito de la justicia se reduce al proceso por el cual las personas se apropian de las cosas. Por tanto, si existe una propiedad en virtud de una adquisición justa o de una transmisión justa, los derechos a esa propiedad no pueden verse afectados por la falta de salud de terceros (Engelhardt, 1995; Arras, 1983). En consecuencia, el acceso a la asistencia sanitaria proviene de la capacidad de pago de los enfermos o de la caridad hacia ellos. Nadie tiene derecho a una asistencia sanitaria excepto si lo ha adquirido a través del mercado. ${ }^{3}$

Algunas variaciones de ese argumento dan cobijo a la garantía de una asistencia mínima, pero bajo unas condiciones determinadas. Una de ellas sugiere que, aun respetando las razones morales que el libertario esgrime contra

3 Una manera retórica que tiene el libertarismo de tratar el tema es aceptar un derecho negativo a la asistencia sanitaria, es decir, un derecho a estar protegido de los daños a la salud infligidos por terceros y a adquirir asistencia sanitaria privada, pero nunca como un derecho positivo o como el deber de proporcionar la atención sanitaria que los demás pueden necesitar si el pagador no ha intervenido en la aparición o desarrollo de la enfermedad (Sade, 1971). 
el derecho a la asistencia sanitaria, la sociedad contemporánea, animada por sentimientos humanitarios y por una tecnología médica que en ocasiones es capaz de restaurar masivamente la salud a un coste relativamente bajo, puede preferir pactar democráticamente una beneficiencia social en materia sanitaria. No obstante, queda claro que sólo el consentimiento democrático otorga legitimidad a la creación de un sistema sanitario que garantice prestaciones mínimas para todos, no la existencia de un derecho moral previo al consentimiento como podría ser el derecho a la salud recogido por los tratados de las Naciones Unidas. La existencia de un sistema sanitario público, aunque mínimo, puede crear la confusión de que existe un derecho a la salud. Esa confusión debe ser pronto esclarecida para que no genere o continúe generando unas expectativas sociales falsas acerca de lo que justifica la provisión de salud (Fried, 1976).

Otra línea de argumentación de impronta libertaria que intenta rebajar la indiferencia hacia la salud de los más pobres defiende que aunque toda intervención pública que implica obtener recursos privados para distribuirlos entre la población es en principio injusta (por las razones ya esbozadas), hay que fomentar el deber moral de la beneficiencia o caridad. Asumiendo ese deber positivo y dados los costes de organización, se puede tolerar una intervención pública en la provisión de un mínimo de asistencia sanitaria para todos. En cualquier caso, los contenidos de la provisión mínima dependerán en todo momento de la voluntad generosa de los donantes, que siempre conservan la libertad de retirar sus ayudas, pero no de razones morales vinculadas a la justicia (Buchanan, 1984; Brody, 1981: Lomasky, 1981).

Así pues, según la tesis libertaria de derechas, si no hay razones de justicia para reducir las desigualdades de salud dentro de un país, tampoco hay razones para denunciar una supuesta injusticia ligada a las desigualdades globales de salud, excepto si dichas desigualdades son el resultado de un daño atribuible a un agente determinado. La única obligación moral hacia los demás que el libertarismo de derechas reconoce es el deber negativo de no dañar a los otros. Cuando se produce ese daño, el infractor, ya sea un Estado, una empresa o un individuo, tiene la obligación de responder por su mala acción, tanto si el daño tiene lugar en el propio país como en otro. Más abajo me referiré a los problemas del argumento libertario de derechas con relación a este punto.

El argumento del estatalismo es diferente. Grosso modo, sostiene que la justicia global es irreal porque toda idea de justicia social implica la existencia de un estado, el único marco político en el que se puede hablar de justicia. Fuera del Estado, puede existir una aspiración moral a la justicia, pero sólo dentro de él se dan las condiciones necesarias para poderla reclamar. Esta concepción de la justicia, típicamente hobbesiana, parte de la idea de que no hay justicia sin una soberanía que la ampare o la legitime. Según Hobbes, no hay justicia sin una institución legítima a quien reclamarla y que, a su vez, 
pueda imponerla, y eso sólo es posible en el marco de un Estado soberano: debe ser soberano porque debe tener la autoridad suficiente para imponer reglas que sean aceptadas por los gobernados; y debe funcionar como un Estado porque debe poseer y ejercer el monopolio de la fuerza. Y esto es independiente de que el razonamiento moral e incluso la motivación moral lleve a los ciudadanos de ese estado a descubrir por sí mismos los principios de la justicia. Una cosa es elaborar una teoría moral de la justicia y otra muy distinta reconocer su legitimidad política. Esto último sólo es posible gracias a un Estado. «Donde no hay un poder común, no hay ley; y donde no hay ley, no hay injusticia» (Hobbes, 1989, 109). La razón es que, para Hobbes, como es bien conocido, en ausencia de un poder soberano los individuos acaban dependiendo únicamente de sus propios recursos y, dominados por la principal motivación de sus vidas, que no es otra que la preservación de uno mismo, entran en una guerra defensiva y de mutua desconfianza. Así pues, si no existe un estado global, tampoco existe la posibilidad de una justicia global. En consecuencia, las desigualdades globales de salud no son injustas aunque muestren una desigualdad inmerecida. En ausencia de un estado mundial, no existe ninguna instancia a la que reclamar o desde la que impartir justicia.

Creo, no obstante, que el argumento proestatalista tiene fisuras. En primer lugar, en ocasiones la desigualdad global de salud es el resultado de la acción de unos Estados contra otros o de multinacionales que operan internacionalmente. Por ejemplo, las guerras injustas que unos Estados perpetran contra otros o el reconocimiento político y los intercambios comerciales con estados que niegan la atención sanitaria mínima y el acceso a unas condiciones de vida digna a sus propios ciudadanos causan o contribuyen a causar desigualdad de salud. La acción de determinadas empresas multinacionales que contaminan en terceros países o que impiden que los sindicatos se organicen en esos países para conseguir mejores condiciones de trabajo, a menudo con la connivencia de gobiernos corruptos, también causan mala salud y desigualdad global de salud. Si las relaciones internacionales están exentas de justicia social, esas acciones quedan impunes desde el punto de vista de la reclamación de justicia. Ese decepcionante resultado es algo que ni siquiera el libertarismo de derechas, comprometidos con el principio de no dañar a terceros, está dispuesto a admitir.

Otro problema es que el estatalismo, al negar la existencia de injusticias globales, se muestra inoperante ante la intución moral de que las desigualdades globales de salud no nos pueden dejar indiferentes, incluso si no están causadas por la acción de terceros países o de empresas transnacionales. Resulta moralmente difícil negar, por ejemplo, que es injusto que los niños de un país pobre como Angola tengan una probabilidad de morir antes de los cinco años setenta y tres veces mayor que los niños nacidos en Noruega. Naturalmente, el estatalismo con rostro humano sostiene que es injusto que el estado angoleño descuide la salud de esos niños o que no los trate con equi- 
dad respecto al resto de niños de su país, y aplaude que los individuos ricos de las sociedades ricas ayuden de algún modo, a título individual o a través de organizaciones sociales no gubernamentales, a paliar esa desgraciada situación. Pero rechaza que los ciudadanos de terceros países tengan la obligación de ayudarles o que la desigualdad global de salud, que hace que los niños mueran antes de lo que deberían por enfermedades fácilmente evitables, sea, por sí misma, una injusticia que el mundo tenga que resolver. Como sentencia Thomas Nagel $(2005,122)$, «a nivel internacional, bien puede haber criterios morales, pero no merecen el nombre de justicia».

El problema de fondo del estatalismo es la asunción de que el marco de la justicia es el Estado nacional westfaliano y que los sujetos de la justicia no pueden ser otros, en consecuencia, que los conciudadanos de un estado territorial. Hoy día, los debates sobre la justicia global están rompiendo esa asunción. Empiezan a cuestionar «el punto de vista según el cual la justicia debe ser únicamente una relación interna entre conciudadanos y articulan nuevas concepciones postwestfalianas acerca de quién cuenta» (Fraser, 2008, 66). El fenómeno de la globalización económica, pero también las luchas políticas que trascienden el marco westfaliano, la constatación de que las economías nacionales no determinan ya el bienestar de los ciudadanos, que los flujos culturales traspasan las fronteras nacionales y que cada vez más las decisiones que afectan a muchos individuos se toman fuera de las fronteras de sus respectivos estados, junto a la proliferación de movimientos sociales transnacionales a favor de los derechos humanos, el feminismo internacional o el medio ambiente, todo ello junto contribuye a debilitar el dogma del estatalismo y la versión de que el quién de la justicia es el ciudadano de un Estadonación.

\section{La salud y los derechos humanos}

Contra las tesis libertarias de derechas y el estatalismo muchos cosmopolitas invocan los derechos humanos. Ya hemos visto, al inicio del artículo, que la OMS se refiere a la salud como un derecho universal, con lo que refrenda la misma Declaración Universal de los Derechos Humanos de 1948 cuando afirma, en el artículo 25, que «toda persona tiene derecho a un nivel de vida adecuado que le asegure, así como a su familia, la salud y el bienestar, y en especial la alimentación, el vestido, la vivienda, la asistencia médica y los servicios sociales necesarios». Otros tratados de las Naciones Unidas sobre derechos humanos han seguido a éstos, como el Pacto Internacional de Derechos Económicos, Sociales y Culturales, adoptado en 1966, en cuyo artículo 12 se lee que «los Estados Partes en el presente Pacto reconocen el derecho de toda persona al disfrute del más alto nivel posible de salud física y mental». El Comité de Derechos Económicos, Sociales y Culturales de las Nacio- 
nes Unidas, que supervisa la aplicación del citado Pacto, adoptó en 2000 una Observación general sobre el derecho a la salud. Dicha Observación general dice que el derecho a la salud no sólo abarca la atención de salud oportuna y apropiada, sino también los principales factores determinantes de la salud, como el acceso al agua limpia potable y a condiciones sanitarias adecuadas, el suministro de alimentos sanos, una nutrición y una vivienda adecuadas, condiciones sanas en el trabajo y el medio ambiente, y acceso a la educación e información sobre cuestiones relacionadas con la salud, incluida la salud sexual y reproductiva. En el año 1989, la Convención sobre los Derechos del Niño declaró que «la vida, la supervivencia, el máximo grado de desarrollo, el acceso a la salud y a los servicios de salud, no son sólo necesidades básicas de los niños y de los adolescentes, sino que constituyen derechos humanos fundamentales».

La conexión entre la salud y los derechos humanos puede establecerse de dos modos distintos. Se puede pensar que la salud es uno más de los derechos humanos fundamentales o que es una precondición del disfrute real de algunos de los derechos humanos básicos. La primera idea resulta controvertida porque no siempre tenemos claro si lo que tenemos es un derecho a la salud o bien a la atención sanitaria. La utilidad de hablar del derecho a la atención sanitaria es que es algo sobre lo que se puede legislar y construir políticas concretas con más facilidad. Sin embargo, el atractivo del derecho a la salud proviene de la constatación de que los determinantes sociales de la salud, como ya hemos comprobado, no se reducen a la atención sanitaria, sino que son múltiples y la mayor parte de ellos están relacionados con las condiciones sociales de vida, como la nutrición, la seguridad laboral, los estilos de vida, la educación, la discriminación de las mujeres, la desigualdad social y la falta de libertades individuales.

Sin embargo, a la hora de concretar el derecho a la salud, nos enfrentamos a problemas que no son fáciles de resolver. Tal vez el más importante de ellos es el hecho de que no tenemos claro qué es exactamente a lo que tenemos derecho. La controversia entre los partidarios de las definiciones objetivas ${ }^{4}$ de salud, los que enfatizan los elementos subjetivos y los defensores del constructivismo social no deja lugar a dudas sobre la complejidad teórica del asunto. Eso provoca que las definiciones de salud, para poder integrar los innumerables factores que intervienen en su concepción, incluidos los factores culturales, acaben siendo demasiado ambiguas.

Y, por si eso no fuera poco, está la cuestión del coste económico. Proporcionar «el goce del grado máximo de salud que se puede lograr» es económicamente insostenible si también queremos satisfacer el resto de derechos hu-

${ }^{4} \mathrm{Ni}$ siquiera hay acuerdo entre los partidarios de una definición objetiva de salud. La OMS considera que la salud es un estado de completo bienestar físico, psíquico y social, mientras que otras definiciones hablan de un déficit en el funcionamiento básico de la especie (Daniels, 2008) o de ausencia de capacidades básicas (Ruger, 2006). 
manos fundamentales. Por esa razon, cualquier aproximación a la salud como un derecho humano universal tiene que dibujar bien los límites en la satisfacción de ese derecho si no quiere convertirse en una declaración vacía.

Una opción es referirse al derecho a la salud como el derecho a un mínimo de salud razonablemente buena en vez de querer alcanzar la salud máxima posible de toda la población mundial. Además, ¿qué supone que todo el mundo logre el goce del grado máximo de salud? ¿que todos alcancemos la esperanza de vida de los japoneses? ¿Cómo podría conseguirse algo así sin un incremento ingente en los presupuestos y una transformación radical de la sociedad? Con el fin de evitar el riesgo de que las declaraciones de derechos sean palabras retóricas y sentimentales, al menos a corto y medio plazo, el Comité de Derechos Económicos, Sociales y Culturales habla de una realización progresiva en vez de una realización completa e inmediata de tales derechos ${ }^{5}$. Otra opción puede ser concentrar los esfuerzos en la protección y la satisfación del derecho a la salud en los problemas de salud más severos que padecen las personas más vulnerables del planeta.

Seguramente, ambas opciones tienen la ventaja de que las discusiones bizantinas sobre las concepciones de la salud y sus múltiples aproximaciones filosóficas y culturales no supondrían un obstáculo para reconocer los problemas de salud verdaderamente graves que existen en el mundo y cuál es el nivel de salud mínima razonable que hay que garantizar. El acceso a una atención sanitaria básica y el disfrute de un mínimo de condiciones de vida saludables son, además, reivindicaciones lo bastante urgentes, dada la escandalosa desigualdad de salud que hay en el mundo, como para que su realización no tenga que esperar a que finalicen los debates filosóficos sobre el verdadero significado de la salud.

Por otra parte, si, después de todo, pensamos que no existe un derecho a la salud, pero reconocemos que la salud es una condición necesaria para poder disfrutar de los derechos humanos fundamentales, no parece que en la práctica varíen las cosas, ya que sería incoherente desatender el compromiso moral con la salud si el objetivo sigue siendo aplicar los derechos humanos con efectividad. El esfuerzo que se deriva de una exigencia moral se deriva también de la otra. Ambas conexiones de la salud con los derechos humanos acaban convergiendo al final.

La conexión de la salud con los derechos humanos conlleva otras ventajas añadidas. Así, los derechos humanos poseen un reconocimiento social y político a nivel internacional del que carece cualquier otra teoría de la justicia.

5 La estrategia que las Naciones Unidas sigue para procurar esa realización progresiva consiste en fortalecer la salud pública a través de cuatro direcciones: reduciendo la prevalencia de enfermedades, discapacidades y muertes evitables en el mundo, promoviendo estilos de vida saludables, construyendo sistemas sanitarios que mejoren equitativamente la salud de todos y promoviendo el reconocimiento de la dimensión social, económica, medioambiental y política de la salud (Tarantola, 2007). 
Además, aunque siempre sigue pendiente la tarea de fundamentar éticamente los derechos humanos, su valor no disminuye por esa razón. Incluso en el momento de su fundación, su falta de fundamentación no fue ningún obstáculo para que se llegase a un acuerdo sobre ellos que se plasmase en una Declaración abierta sobre su universalidad. Como señaló en su momento Jacques Maritain, uno de los filósofos que ayudó a elaborar los materiales sobre los que se debatió la Declaración Universal, «durante una de las reuniones de la Comisión Nacional Francesa de la UNESCO en la que se discutían los Derechos del Hombre, alguien se sorprendió al ver que ciertos defensores de ideologías violentamente opuestas hubiesen llegado a un acuerdo sobre el borrador de una lista de derechos. "En efecto - replicaron ellos - estamos de acuerdo en lo tocante a estos derechos, pero con la condición de que no se nos pregunte el porqué"» (Maritain, 2002, 84, cursivas en el original).

Otra de las ventajas de asociar la salud a los derechos humanos es que ayuda a que las exigencias éticas en la promoción de la salud pasen con más facilidad de la retórica a la realidad. El lenguaje de los derechos permite transformar el derecho a la salud en un instrumento legal, una herramienta constructiva y crucial para que los gobiernos y los países se comprometan efectivamente a mejorar la salud de la gente. Eso no significa que la conversión de los derechos en leyes sea automática o sencilla. Norman Daniels $(2008,335)$ nos recuerda que la existencia de las declaraciones sobre derechos humanos, aunque forma parte de numerosas legislaciones políticas nacionales e internacionales, no ha conseguido hasta la fecha generar las obligaciones globales deseadas en relación a la salud y la atención sanitaria. Sin embargo, otro peso pesado del debate filosófico sobre las desigualdades globales de salud, Amartya Sen (2008), replica que, si bien aún hay mucho por lograr en el ámbito de la legalidad internacional y, sobre todo, de su cumplimiento, un derecho humano tiene utilidades complementarias a la de transformarse en leyes efectivas: contribuye de una manera poderosa y necesaria a tomar conciencia colectiva y a fortalecer la lucha por los contenidos de dicho derecho en otros ámbitos sociales, como la discusión pública, el trabajo de investigación o el trabajo social.

Pero la vinculación de la salud con los derechos humanos tiene, a mi entender, otros problemas. Algunos de ellos son comunes a la misma idea de derechos humanos, como la más que probable inflación de derechos (la proliferación de derechos humanos trae consigo su debilitamiento), el conflicto con otros derechos (el derecho a la salud se ve perjudicado por el derecho a elegir libremente la atención sanitaria que uno necesita o quiere, lo que refuerza a la sanidad privada que pueden pagar los más ricos en detrimento de la pública), y las críticas habituales a los derechos humanos por su excesivo individualismo (con la consiguiente marginación de los temas de salud pública, pese a que probablemente son más importantes que el acceso individual a los recursos de salud) y paternalismo (enfatizando en las víctimas su condi- 
ción de víctimas y desincentivando así su propia emancipación). Pero, aun dejando de lado estas críticas, hay dos grandes dificultades a las que tiene que enfrentarse la teoría de los derechos humanos si quiere dar respuesta a las desigualdades globales de salud. La primera es que los Estados, pese a ser los principales agentes en la protección de los derechos humanos, no demuestran por lo común tener la suficiente voluntad política para abordar esa tarea (Chapman, 2009) y la segunda es que el lenguaje de los derechos resulta demasiado ambiguo para determinar las obligaciones (O’Neill, 2002).

Los Estados están mostrando una evidente incapacidad para dar respuesta a los problemas de salud en el mundo, incluidos los más graves. No sólo no ofrecen la ayuda necesaria para disminuir las muertes prematuras y evitables a causa de enfermedades fácilmente tratables o para luchar contra la desnutrición más severa, que mata, por ejemplo, a más de dos millones de niños anualmente, sino que, sobre todo los Estados más ricos, utilizan todos sus recursos para influir en la legislación internacional con el objetivo de blindar los intereses económicos nacionales (o de empresas nacionales) pese a que la consecuencia directa de esa política proteccionista sea el empeoramiento de la salud en el mundo. Piénsese, por ejemplo, en el aumento de la protección de las patentes farmacéuticas en los últimos años (Pogge, 2009). Por otra parte, los Estados más pobres, además de su endémica falta de recursos y de la tradicional desatención a la salud de sus ciudadanos — salvo encomiables excepciones- tienen problemas añadidos, como la obligación de pagar la deuda externa que les reclaman las instituciones internacionales y la fuga de profesionales sanitarios a países ricos (Kuehn, 2007), que dificultan aún más su capacidad para dar solución a los problemas de salud de sus respectivos ciudadanos.

Además, aunque los Estados contribuyen a aumentar los problemas graves de salud en el mundo (a través de las guerras injustas en terceros países, la opresión y la violencia internas, la venta internacional de armas, etcétera), no son los únicos. Las grandes empresas transnacionales y las instituciones internacionales, como el Fondo Monetario Internacional, el Banco Mundial o la Organización Mundial del Comercio, que a menudo ignoran las consecuencias sociales y para la salud de sus políticas económicas, suelen tener más poder que los propios Estados a la hora de influir en las decisiones que afectan a la salud de la población mundial y, en cambio, el modelo de los derechos humanos, centrado principalmente - a veces parece que incluso exclusivamente - en la responsabilidad de los Estados, no les exige el mismo grado de cumplimiento con esos derechos ${ }^{6}$.

Por otra parte, el lenguaje de los derechos humanos es ambiguo a la hora de determinar las obligaciones morales. El derecho a la vida, el derecho a la

6 Para ver el tipo de responsabilidad que se podría exigir a los actores internacionales no estatales en la reducción de la desigualdad y la mala salud en el mundo, véase Buchanan y Decamp (2006). 
salud, el derecho al desarrollo, son frases afortunadas pero que no indican con claridad, en el contexto internacional, quién tiene la obligación de cumplir con esos derechos. La ausencia de un Estado global y de la capacidad realmente coactiva de instituciones políticas globales, como las Naciones Unidas, convierten el lenguaje de los derechos humanos en una retórica desesperante. Ni siquiera cabe esperar que las declaraciones de derechos tengan una sola interpretación y obliguen en una dirección común. Les falta concretar quién tiene que hacer qué y a quién. En este sentido, el lenguaje de los derechos tiene que complementarse, en una teoría ética, incluida la ética de la salud, con el de los deberes. Como señala Onora O’Neill, «si queremos establecer normas intelectualmente robustas para las políticas de salud sería preferible comenzar por dar cuenta sistemática de cuáles son las obligaciones en vez de los derechos» (O’Neill, 2002, 42). Sólo así podremos persuadir a los que realmente pueden ayudar a los demás de que deben hacerlo y de cómo pueden hacerlo y crear, si es necesario, las instituciones internacionales oportunas para perseguir los objetivos morales relacionados con la salud a nivel global.

\section{De los derechos a los deberes}

El filósofo que más está haciendo en la actualidad por concretar la idea de los deberes morales hacia las personas más vulnerables del planeta, también en los temas de salud, es, sin duda, Thomas Pogge. Animado por la convicción cosmopolita de que los individuos - y no los Estados o las comunidades nacionales - son las unidades últimas de la moral y de que es irreal pensar que los problemas de salud en el mundo se pueden resolver de fronteras hacia adentro, en los últimos años Pogge está tratando de construir una teoría ética que no se limita a justificar la bondad de la ayuda internacional en materia de salud, sino que incluye propuestas concretas sobre cómo se puede involucrar a los Estados y a la industria farmacéutica en esa ambiciosa y urgente empresa moral. ${ }^{7}$ Junto a la defensa de los derechos humanos aplicados a la salud, Pogge propone que partamos del deber negativo de no dañar a los demás como base de nuestra obligación de asistencia a los pobres y los enfermos del mundo (Pogge, 2005a).

Con el fin de entender la naturaleza de los deberes morales negativos, hay que empezar hablando de los deberes morales positivos, que son los que tradicionalmente se invocan a favor de la justicia global. El argumento cosmopolita de Peter Singer es una excelente muestra de la defensa de la justicia global a partir de los deberes positivos. En un texto pionero sobre la justicia global, Sin-

7 En este artículo, me limito a analizar la cuestión normativa de su teoría. Las propuestas concretas se pueden encontrar en su ya abundante bibliografía, que el autor actualiza regularmente en su página web (http://pantheon.yale.edu/ tp4/index.html). 
ger (1972, 231-232) expone con claridad la exigencia ética de su cosmopolitismo: «si está en nuestro poder evitar un mal sin tener que sacrificar nada de importancia moral comparable, entonces lo debemos hacer... y no hay diferencia moral si la persona que puedo ayudar es el hijo de un vecino que vive a diez yardas de mí o un bengalí cuyo nombre no conoceré nunca, que vive diez mil millas más lejos». No es necesario que hayamos causado el mal evitable que surge en cualquier parte del mundo. Su misma existencia y nuestra capacidad para paliarlo son razones suficientes para justificar el deber de ayudar a quien lo padece. Podríamos afirmar que si no aliviamos el mal existente, teniendo la capacidad para ello, allí donde se produce, de algún modo nos convertimos en cómplices de que ese mal continúe existiendo. El daño que toleramos por omisión es tan malo como el daño que infligimos por acción.

Sin embargo, la propuesta de Singer tiene serias limitaciones desde el punto de vista de la justicia global. En primer lugar, el deber de ayudar a cualquier persona necesitada en cualquier parte del planeta conlleva una sobrecarga de obligaciones imposible de afrontar para cualquier individuo. En segundo lugar, reducir el deber de ayudar a los más necesitados a la ayuda individual, a la acción personal, es a todas luces irrealista, porque no es razonable esperar que los individuos dediquen toda su vida a ayudar a los demás; es también ineficaz, porque deja sin cuestionar y sin afrontar las causas de las injusticias en el mundo; y es injusto con los verdaderos causantes de los males planetarios, cuya responsabilidad moral parece equipararse a la de los que se limitan a tolerar el mal por omisión. Finalmente, el argumento de Singer tiene el problema de que parece invocar deberes que sólo obligan en conciencia y que fácilmente se confunden con deberes de beneficencia o caridad, muy lejos de los deberes de justicia que debería proponer la justicia global.

Pogge intenta eludir algunas de esas dificultades introduciendo en el debate de la justicia global una idea de obligación moral mucho más fuerte que la de Singer. Si el filósofo australiano asocia las obligaciones morales con los deberes positivos de ayudar a quien lo necesita, con independencia de si somos los causantes de su mal o no, Pogge considera que es posible fundamentar la ayuda a los más pobres del planeta en la idea de deberes negativos, es decir, en el deber de no dañar a otros. Según el filósofo norteamericano de origen alemán, no hay duda de que si dañamos a alguien tenemos la obligación moral de reparar ese daño (no hay libertad sin responsabilidad) y eso es cierto con independencia de si la persona dañada es extranjera o nacional, o de si causamos el daño en nuestro país o en otro. Si, por ejemplo, atropellamos a un ciclista mientras conducimos por una carretera en el extranjero, el hecho de estar fuera de nuestro país y sujetos a leyes foráneas no nos exime de idéntica responsabilidad moral, aunque en aquel territorio ninguna ley nos condene por nuestra infracción.

Pues bien, Pogge sostiene con razón que muchas de las calamidades y precariedades que sufren los habitantes de los países más pobres del mundo, 
incluida la mala salud, han sido provocadas, directa o indirectamente, en el presente o en el pasado, por la intervención de los países más ricos y poderosos, de manera que ahora éstos no pueden eludir su responsabilidad en repararlas. Según Pogge, el ciudadano de los países ricos debe asumir la responsabilidad por los actos de explotación, expoliación y otras barbaridades cometidas contra las personas que habitan en los lugares generalmente más pobres de la tierra. Todos los que contribuyen a la imposición de un orden global injusto que crea las condiciones de pobreza y miseria mundial como también todos los que sacan provecho de esa injusticia tienen la obligación de reparar ese daño. El deber de ayudar a los más necesitados deja de ser un simple deber positivo, que prescribe que hay que ayudar al necesitado porque lo necesita, y se convierte así en un deber negativo y, por tanto, moralmente mucho más fuerte, ya que se deriva de la obligación de no hacer el mal y no simplemente de la de hacer el bien. Además, Pogge cree que, de ese modo, la justicia global se muestra más atractiva y fácil de asumir para los libertarios de derechas, reacios a considerar que el Estado tiene derecho a imponer a sus ciudadanos reglas de conducta solidaria, con lo que su argumento a favor de la justicia global generaría mucho más consenso que el de Singer, o al menos eso espera Pogge (2005b, 36).

Sin embargo, creo que el argumento de Pogge no es del todo convincente. En primer lugar, no se puede demostrar que el orden global sea la causa de toda la pobreza y la desigualdad de salud que recorre el mundo. Es cierto que la globalización impone unas relaciones de mercado asimétricas que contribuyen a mantener y a veces a agudizar la pobreza global, pero es difícil sostener que toda la pobreza y la mala salud se derivan de esa imposición injusta. Si Pogge quiere tener éxito con su argumento, tiene que demostrar que no existen causas endógenas en la pobreza y la desigualdad de salud a nivel global, causas que no son reducibles al impacto del sistema económico internacional que imponen los países ricos. Pogge acierta cuando afirma, contrariamente a lo que pensaba Rawls $(2001,127-8)$, que los pobres del planeta no tienen por definición la culpa de su situación. Aunque la corrupción de las élites gobernantes está ampliamente extendida en los países menos desarrollados y el nivel tecnológico de estos países es por lo general deficiente, las principales causas de la pobreza global son probablemente exógenas, incluyendo los grandes incentivos de los países ricos para que se perpetúe la corrupción política en los países pobres. Pero de ahí no se deriva que los ricos del planeta sean completamente responsables de la miseria que azota el mundo. Pogge excluye de su argumento todas las causas de la desigualdad global de salud que no se puede demostrar que han sido creadas o instigadas por los países ricos o sus ciudadanos, como, por ejemplo, las que son el resultado del azar natural (accidentes, catástrofes, enfermedades genéticas ${ }^{8}$...) o de guerras

${ }^{8}$ Imaginemos que, en un país pobre, un niño con una discapacidad de origen genético no 
locales (con orígenes a veces ancestrales, no achacables a terceros países ${ }^{9}$ ), las que están vinculadas a costumbres y prácticas culturales locales (como el caso de las enfermedades que se contraen o transmiten por estilos de vida arraigados por la tradición local) o las que dependen de políticas sociales escogidas soberanamente por cada país.

Sobre ese último punto, imaginemos que un determinado país no invierte lo suficiente en sanidad y buenas condiciones de vida de su población porque prefiere destinar la inversión a producir otros bienes. ¿Podemos entonces afirmar que la desigualdad de salud entre ese país y el resto es injusta? Los casos de Cuba y el Estado indio de Kerala, con unos índices de salud de la población muy buenos a pesar de ser pobres, demuestran que existe una gran responsabilidad endógena en la desigualdad de salud de la población. Por tanto, aunque podemos pensar que dicha desigualdad es una injusticia, ¿por qué deberíamos ayudar a los países que tienen una renta similar a la de Cuba y Kerala pero que no invierten tanto como ellos en disminuir las desigualdades de salud? Podemos pensar que muchos de esos países pobres no son democráticos o que están dominados por la corrupción y que, en consecuencia, la voluntad de su población está abiertamente secuestrada, pero entonces tal vez los deberes que impone la justicia global deben comenzar por ayudar a democratizar esos países y no por eximirlos de sus obligaciones sanitarias.

Una de las ventajas de los deberes negativos en una teoría de la justicia global es el supuesto poder ecuménico que Pogge le otorga, puesto que, según él, pueden integrar al pensamiento libertario de derechas en las exigencias de una teoría de la justicia global. Sin embargo, no está claro que el argumento de los deberes negativos logre esa integración. Pogge presupone que los países pobres están peor de lo que deberían estar sin la intervención abusiva de los países ricos en el orden global. Pero esa suposición no tiene por qué ser compartida por un libertario de derechas, que puede pensar que si bien uno debe hacerse cargo del mal infligido a los demás, no debe hacerlo hasta el punto de dejar a la víctima mucho mejor de lo que estaba o de lo que hubiera estado de no haber mediado el abuso. Con la propuesta de Pogge de erradicar la pobreza extrema se puede camuflar, después de todo, un deber positivo que el libertario de derechas rechazaría como base de una obligación moral (Gilabert, 2007, 212) ${ }^{10}$. Probablemente, una teoría de la justicia global

recibe el tratamiento médico que sí pueden obtener los niños de los países ricos. Si nadie es el responsable de esa enfermedad, ¿no existe igualmente el deber de justicia de ayudarle desde terceros países? Si ese deber existe, no tiene la forma de un deber negativo, sino de uno positivo. Así pues, necesitamos a los deberes positivos para completar una teoría de la justicia global.

9 Que los países ricos vendan las armas que alimentan las guerras en los países pobres no exime a estos últimos de parte de la responsabilidad por utilizarlas.

10 Por otra parte, la propuesta de Pogge tiene la ambición no sólo de compensar a los pobres de todo el mundo por su pobreza injustamente inducida, sino también de transformar el orden global establecido, lo que tampoco cuadra con la perspectiva moral de un libertario de derechas (Meith, 2008, p. 23). 
debería prescindir del beneplácito de los libertarios de derechas para poder prosperar ${ }^{11}$.

Pogge no afirma que no existan deberes positivos. Lo que afirma es que los deberes negativos tienen un papel fundamental en una teoría de la justicia global, y eso es muy ventajoso para dicha teoría, porque «los deberes negativos tienen mayor fuerza moral que los deberes positivos cuando todo lo demás que está en juego permanece constante» (2005b, 34). Mi objeción es que los deberes positivos son indispensables en una teoría de la justicia global, y lo son tanto que minimizar su papel provoca también rebajar el alcance de la teoría. Es necesario enfatizar que los ricos globales tengan la obligación de paliar la pobreza y la desigualdad global de salud que ésta produce sólo si han contribuido a crearla.

El problema de los deberes positivos es que no resulta tan fácil convertirlos en deberes de justicia como al referirnos a los deberes negativos. Es fácil pensar que tenemos el deber o la obligación de no agredir a los otros. Pero ¿tenemos idéntica obligación de ayudarles en caso de necesidad, sobre todo si se trata de personas muy distantes a nosotros y a las que no les hemos hecho ningún daño, por muy deseable que nos parezca ese deber? Puede que tengamos la obligación de ayudar a los demás en caso de necesidad, pero ¿se trata de una obligación forzosa, como la que tenemos para cumplir una ley, o tan sólo es un acto opcional, cuyo incumplimiento no acarrea ningún tipo de sanción seria? En lenguaje kantiano, la obligación de no dañar a los otros se denomina perfecta, porque es una obligación estricta, que me dice que debo (o que no debo) hacer algo porque ésa es la voluntad de todos. En cambio, la obligación de auxiliar a una persona que se encuentra en peligro es imperfecta $\mathrm{o}$, lo que es lo mismo, la ley que me obliga a ello pertenece únicamente a mi propia voluntad. La obligación imperfecta es también un deber moral, pero, si no quiero, no tengo que dar cuenta a los demás de su cumplimiento o incumplimiento, ni los demás tienen que exigirme cuentas a mí. «Los deberes imperfectos son sólo deberes de virtud. Cumplirlos es un mérito, pero transgredirlos no es un demérito» (Kant, 1999, 243). En un lenguaje más popular y en relación a la justicia global, la cuestión es si los ricos y los poderosos globales tienen el deber de justicia de asistir a los pobres y a los vulnerables globales aun sin haber causado o contribuido a causar su situación de precariedad, o si dicha asistencia es una cuestión de beneficencia o caridad y, por

11 Siendo realistas, creo que si alguien está dispuesto a asumir la responsabilidad derivada de un deber negativo tiene cierta predisposición a asumir también la que se deriva de un deber positivo bien fundamentado. En cambio, alguien que no está dispuesto a asumir las obligaciones derivadas de un deber positivo no tiene tampoco mucha predisposición a asumir las que provienen de un deber negativo. Naturalmente, hay un fondo empírico en esta observación que no puedo probar. Pero dicha observación no me parece irrealista. A veces, las distinciones filosóficas presuponen una idea equivocada de la experiencia moral de las personas. Si tengo razón, entonces la insistencia en basar los deberes de justicia exclusivamente en los deberes negativos no tiene las ventajas prácticas o ecuménicas que Pogge espera de ello. 
tanto, moralmente opcional. He tratado de aportar luz a este problema crucial en otro sitio (Puyol, 2011).

\section{Igualdad, prioridad, suficiencia y salud}

Dejando a un lado la cuestión de la obligación moral, queda todavía el asunto de qué criterio de justicia es el más adecuado para afrontar las enormes desigualdades de salud que hay en el mundo. Una teoría de la justicia global igualitarista puede proponer hasta tres enfoques diferentes: la igualdad estricta, el prioritarismo y el suficientismo.

La igualdad estricta propugna que los individuos alcancen un mismo nivel de resultado (Scanlon, 2000). En este caso, puede tratarse de la salud propiamente - igualdad de salud - o del acceso igualitario a la atención sanitaria. Por ejemplo, un objetivo estrictamente igualitario en materia de salud a nivel global podría ser la nivelación de la esperanza de vida de todos los habitantes del planeta o la igualdad de resultados en la utilización de las tecnologías médicas disponibles. El problema del primer objetivo es que el coste económico de lograr que la esperanza de vida de todo el mundo sea como la de los japoneses o la de los suecos es inasumible. En un contexto de recursos limitados, el objetivo de la igualdad de salud es imposible de llevarse a cabo a menos que disminuyamos la esperanza de vida media del planeta, lo que a todas luces es moralmente inapropiado. Respecto al segundo objetivo, resulta contradictorio defender el acceso igualitario a la atención sanitaria si al mismo tiempo deseamos priorizar a los enfermos por sus necesidades de salud.

Un segundo enfoque igualitarista consiste en priorizar a los que están peor (Parfit, 2000). El objetivo ahora es mejorar la situación de los más desafortunados y, a partir de ahí, ir beneficiando a los demás en función de su posición en una escala de privaciones. En la práctica, eso puede significar dar prioridad a las políticas de salud que benefician a los que tienen una esperanza de vida más baja o a los que están más enfermos o a los que tienen un peor índice de bienestar. Uno de los problemas de este enfoque es que al dar prioridad a uno de los factores señalados, podemos colocar en la cola de la prioridad a la misma persona en otro de los factores. Por ejemplo, podríamos, paradójicamente, acabar ayudando antes a enfermos con muy mala salud pero ricos que a enfermos sólo ligeramente menos graves pero claramente más perjudicados por los determinantes sociales de la salud. Se puede replicar que esa paradoja se elimina si priorizamos a los enfermos de las clases sociales más bajas, pero eso no evita la paradoja consiguiente de que podríamos ahora favorecer a pobres con buena salud en vez de a enfermos ligeramente menos pobres con mucha peor salud.

Un segundo problema es que, en un contexto de recursos limitados, si priorizamos a enfermos muy graves con tratamientos muy caros, podríamos 
dejar sin atender a numerosos enfermos cuyos tratamientos son más efectivos y a un coste menor, lo que perjudica a los enfermos que precisamente más beneficio potencial en salud pueden obtener, además de que sucumbimos de nuevo a la nivelación por abajo, como hemos visto con el criterio de la igualdad estricta.

El tercer enfoque tiene como finalidad alcanzar un resultado suficiente para todos (Frankfurt, 1987). Aplicado a la salud, el objetivo podría ser que la esperanza de vida y el disfrute de un determinado nivel de salud fuesen para todo el mundo mucho más elevados de lo que son ahora. Dicho objetivo no propone, por ejemplo, que todos vivamos tanto como pueden hacerlo los japoneses, pero exige que no se espere que nadie muera antes de una determinada edad considerada como razonablemente alta. Teniendo en cuenta que la esperanza de vida más alta en el mundo sobrepasa ya los ochenta años, no sería descabellado proponer un umbral entre sesenta y cinco y setenta años de edad. No es fácil llegar a un consenso en este punto porque las personas viven en entornos diferentes y no comparten una misma concepción de la salud y de lo que ésta significa en el conjunto de sus vidas. Por esa razón, creo que podemos partir del concepto de capacidades básicas de Sen y flexibilizar el umbral de salud en función del reconocimiento de las capacidades básicas que una persona necesita tener en su entorno vital (Achayra, 2004; Ruger, 2009). El criterio seniano de las capacidades permite ajustar el umbral deseable de salud a las circunstancias de cada persona y de su entorno sin necesidad de universalizar o de prefijar una edad o un estilo de vida saludable, pero, al mismo tiempo, sin renunciar a una cierta objetividad a la hora de comparar estados de salud entre personas con unas circunstancias vitales muy diferentes entre sí. La comparación interpersonal es imprescindible para determinar la injusticia de los resultados y creo que el criterio de las capacidades permite determinar cuáles son las desigualdades injustificadas sin necesidad de comprometerse con una concepción universal de la buena salud. El umbral de suficiencia en salud podría actuar análogamente a como lo hace el umbral de la pobreza, es decir, ajustando los niveles de deseabilidad moral a las circunstancias de cada país, a lo que una persona que vive en él es capaz de hacer y de ser con la cantidad de ingresos (en el caso de la pobreza) o de salud de que dispone.

El criterio de la suficiencia tiene que enfrentarse al menos a dos grandes objeciones. La primera es que se podría pensar que, dado que muchas personas tienen muy difícil alcanzar un umbral de suficiencia alto debido a su mala salud natural, la obsesión por acercarlas a ese umbral resultaría económicamente muy costosa, tanto que obligaría a disminuir las posibilidades de los más sanos de superar con creces el umbral prefijado. Esta objeción, sin embargo, queda anulada si adaptamos el objetivo de la suficiencia no al hecho de que todos alcancen el umbral deseable, sino de que maximicemos el número de personas que pueden hacerlo. En segundo lugar, se puede objetar que 
el criterio de la suficiencia permite cualquier nivel de desigualdad global de salud por encima del umbral. Ésta es una crítica que no se puede rebatir completamente, pero pienso que se puede minimizar. Por un lado, la desigualdad actual es tan grave y la necesidad de paliarla tan urgente que creo que es moralmente preferible centrarse en la posibilidad más realista de disminuir sus peores consecuencias que perseguir ciegamente el objetivo utópico de eliminarla por completo. Por otro lado, teniendo en cuenta lo que sabemos sobre los determinantes sociales de la salud, no hay otro camino para paliar las desigualdades globales de salud, incluyendo el que propone el enfoque de la suficiencia, que reducir las desigualdades sociales y económicas a nivel global. En otras palabras, no se puede alcanzar el umbral de salud suficiente para todos sin rebajar al mismo tiempo los efectos desiguales de los determinantes sociales de la salud. Por tanto, el criterio de la suficiencia no es incompatible con el objetivo último de reducir todas las desigualdades injustas de salud. Al contrario, trabaja en esa misma dirección.

\section{BIBLIOGRAFÍA}

Achayra, A. (2004): «Toward Establishing a Universal Basic Health Norm», Ethics and International Affairs, 18, 3.

Arras, J. (1983): «The Neoconservative Health Estrategy. Vouchers and the Rethoric of Equity», en R. BAYER, A. CAPlan y N. Daniels (eds.), In Search of Equity. Health Needs and the Health Care System, Nueva York, Plenum Press.

BRODY, B. (1981): «Health care for the haves-not: toward a just basis of distribution», en E. E. SHelp (ed.), Justice and Health Care, Dordrecht, Reidel Publishing Company.

Buchanan, A. (1984): «The Rigth to a Decent Minimun of Health Care», Philosophy and Public Affairs, 13, 2.

BuChanAn, A. y DeCAMP, M. (2006): «Responsability for global health», Theoretical Medicine and Bioethics, 27.

Chapman, A. R. (2009): «Globalization, Human Rights, and the Social Determinants of Health», Bioethics, 23, 2.

Daniels, N. (2008): Just Health, Nueva York, Cambridge U.P.

Descartes, R. (1986): Discurso del método, Madrid, Espasa-Calpe.

Engelhardt, H. T. (1995): Los fundamentos de la bioética, Barcelona, Paidós.

FrankfurT, H. (1987): «Equality as a Moral Ideal», Ethics, 98.

FrASER, N. (2008): Escalas de justicia, Barcelona, Herder.

Freeman, K. (1971): Ancilla to the Pre-Socratic Philosophers, Oxford, Blackwell.

FRIED, Ch. (1976): «Equality and rights to health care», Hastings Center Report, 6.

Gilabert, P. (2007): «Comentarios sobre la concepción de la justicia global de Pogge», Revista Latinoamericana de Filosofia, XXXIII, 2.

HobBes, T. (1989): Leviatán, Madrid, Alianza.

Kant, I. (1999): La Metafísica de las Costumbres, Madrid, Tecnos.

KaWACHI, I. y Kennedy, B. P. (2002): The Health of Nations: Why Inequality Is Harmful to Your Health, Nueva York, The New Press. 
Kuenn, B. M. (2007): «Global Shortages of Health Workers, Brain Drain Stress Developing Countries», JAMA 24 Oct., 298 (16).

LOMASKY, L. (1981): «Medical progress and national health care», Philosophy and Public Affairs, 10.

Maritain, J. (2002): El hombre y el Estado, Madrid, Encuentro.

MARMot, M. (2004): The status syndrome: how social standing affects our health and longevity, Nueva York, Owl Books.

- (2010): The Fair society, healthy lives, University College, Londres.

MeITH (2008): «World Poverty as a Problem of Justice? A Critical Comparison of Three Approaches», Ethical Theory and Moral Practice, 11.

Nagel, T. (2005): «The problem of Global Justice», Philosophy and Public Affairs, $33,2$.

Nozick, R. (1988): Anarquía, estado y utopía, México, FCE.

OMS (2008): Subsanar las desigualdades en una generación: alcanzar laequidad sanitaria actuando sobre los determinates sociales de la salud, Informe final de la Comisión OMS sobre Determinates sociales de la Salud, 28 de agosto de 2008.

- (2010): World Health Statistics.

O’NeILl, O. (2002): «Public Health or Clinical Ethics: Thinking beyond Borders», Ethics and International Affairs, 16, 2.

Parfit, D. (2000): «Equality or Priority?», en M. Clayton y A. Williams (eds.), The Ideal of Equality, Nueva York, Macmillan.

Pogge, T. (2005a): La pobreza en el mundo y los derechos humanos, Barcelona, Paidós.

- (2005b): «Real World Justice», The Journal of Ethics, 9.

- (2007): «¿Qué es la justicia global?, Revista Latinoamericana de Filosofia, XXXIII, 2.

- (2009): «Health Care Reform that Works for the U.S. and for the World's Poor», Global Health Governance, II, 2.

Porter, R. (1997): The Greatest Benefit to Mankind, Londres, Fontana Press.

PuYOL, A. (2011): «El derecho a subsistir y la justicia global», manuscrito.

Rawls, J. (2001): El derecho de gentes, Barcelona, Paidós.

Ruger, J. P. (2006): «Towards a Theory of a Right to Health: Capability and Incompletely Theorized Agreements», Yale Journal of Law and Humanities, 18.

Rodríguez, M. y Urbanos, R. (eds.) (2008): Desigualdades sociales en salud, Barcelona, Masson.

SADE, R. M. (1971): «Medical Care as a Right: A Refutation», New England Journal of Medicine, 285.

SCANLON, T. (2000): «The Diversity of Objections to Inequality», en M. CLAYTON y A. Williams (eds.), The Ideal of Equality, Nueva York, Macmillan.

SchIEBER, G. et al. (2007): «Financing Global Health: Mission Unaccomplished», Health Affairs, 26, 4.

Sen, A. (1981): Poverty and Famines, Oxford, Clarendom Press.

- (2008): «Why and how is health a human right?», The Lancet, vol. 372, Dec. 13.

SESPAS (2000): La salud pública ante los desafios de un nuevo siglo. Informe SESPAS 2000, Granada, Escuela Andaluza de Salud Pública.

Singer, P. (1972): «Famine, Affluence, and Morality», Philosophy and Public Affairs, 1, 3. 
Tarantola, D. (2007): «Global Justice And Human Rights: Health And Human Rights In Practice», Global Justice: Theory Practice Rhetoric, 1.

WiKLER, D. (2002): «Personal and Social Responsibility for Health», Ethics \& International Affairs, 16: 47-55.

WILKINSON, R. (2005): The Impact of Inequality. How to make sick societies healthier, Londres, Routledge. 